from TNF- $\alpha$ and IL-6, depending on the degree of weight loss was not detected.

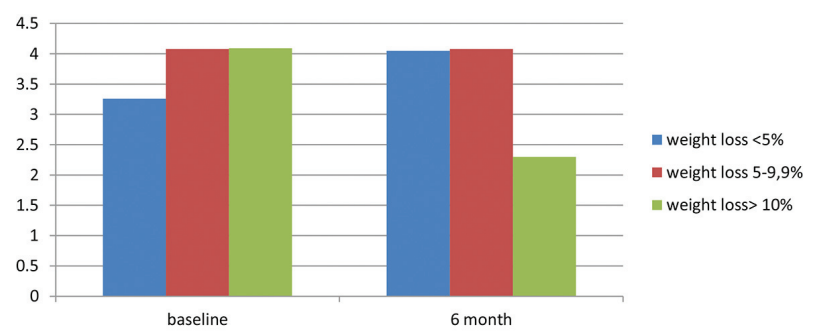

Abstract THU0457 - Figure 1. Dynamics of CRP depending on the degree of weight loss $(p<0.05)$

Conclusion: The results of the study demonstrated a significant effectiveness of the complex treatment of obesity in patients with knee OA, compared with the use of only non-pharmacological methods of weight loss. A decrease in body mass of more than $5 \%$ helps to improve the clinical manifestations of knee $\mathrm{OA}$ and the quality of life of patients. A decrease in body weight of more than $10 \%$ demonstrates a decrease in the level of CRP, which suggests an effect on meta-inflammation in OA.

Disclosure of Interests: Ekaterina Strebkova: None declared, Ludmila Alekseeva Speakers bureau: Bayer, Boeringer-ingelheim, Gedeon-Richter, Servier DOI: 10.1136/annrheumdis-2019-eular.6793

\section{THU0458 EFFICACY AND SAFETY FROM A PHASE 2B TRIAL OF SM04690, A NOVEL INTRA-ARTICULAR WNT PATHWAY INHIBITOR FOR THE TREATMENT OF OSTEOARTHRITIS OF THE KNEE}

Yusuf Yazici ${ }^{1}$, Timothy Mcalindon ${ }^{2}$, Allan Gibofsky ${ }^{3}$, Nancy Lane ${ }^{4}$

Christian Lattermann $^{5}$, Nebojsa Skrepnik ${ }^{6}$, Christopher Swearingen ${ }^{1}$,

Anita Difrancesco ${ }^{1}$, Jeyanesh Tambiah ${ }^{1}$, Marc Hochberg ${ }^{7}$. 'Samumed, LLC, San

Diego, United States of America; ${ }^{2}$ Tufts Medical Center, Boston, United States of

America; ${ }^{3}$ Weill Cornell Medical College, New York, United States of America; ${ }^{4}$ UC Davis Medical Center, Davis, United States of America; ${ }^{5}$ Brigham and Women's Hospital, Boston, United States of America; ${ }^{6}$ Tucson Orthopedic Institute, Tucson, United States of America; ${ }^{7}$ University of Maryland School of Medicine, Baltimore, United States of America

Background: A phase 2a study of SM04690, a small-molecule, intra-articular (IA) Wnt pathway inhibitor reduced knee pain and improved physical function and medial joint space width (mJSW) at 52 weeks in subgroups of subjects with unilateral symptomatic knee osteoarthritis (OA) compared to placebo $(\mathrm{PBO}){ }^{1}$

Objectives: A 24-week phase $2 \mathrm{~b}$ study was conducted to refine patientreported outcome (PRO) measures, target population, medication dose, and to evaluate safety. PRO results for Weeks 12 and 24 are presented here.

Methods: Study subject inclusion criteria required ACR-defined knee OA, Kellgren-Lawrence (KL) grades 2-3, and Pain Numeric Rating Scale (NRS) $\geq 4$ and $\leq 8$ in the target knee and $<4$ in the contralateral knee. A single IA injection of $2 \mathrm{~mL} S M 04690(0.03,0.07,0.15$, or $0.23 \mathrm{mg})$, vehicle $\mathrm{PBO}$, or sham (dry needle only) was given in the target knee at baseline. PRO endpoints included change from baseline in weekly average of daily pain in the target knee by NRS diary (NRS) [0-10], Western Ontario and McMaster Universities Osteoarthritis Index (WOMAC) Pain [0-100], WOMAC Physical Function [0-100], and Patient Global Assessment (PtGA) [0-100]. Differences between active treatment groups and vehicle PBO were analyzed with baseline-adjusted analysis of covariance (ANCOVA).

Results: 695 subjects (mean age 59.0 [ \pm 8.5$]$ years, BMI 29.0 [ \pm 4.0$]$ kg/ $\mathrm{m}^{2}$, female $58.4 \%$, KL3 57.3\%) were enrolled and dosed; 635 subjects (91.4\%) completed the study. No meaningful differences in the incidence of adverse events were observed between treatment and control groups. In the Full Analysis Set, significant improvements from baseline compared to vehicle PBO were observed in pain NRS for $0.07 \mathrm{mg}$ (Week 12 $[P=0.001]$, Week $24[P=0.031]$ ) and $0.23 \mathrm{mg}$ (Week $12[P=0.012]$, Week $24[P=0.022])$ SM04690 dose groups (Figure). Similar improvements were observed in WOMAC Pain for $0.07 \mathrm{mg}$ (Week $12[P=0.04]$ ) and $0.23 \mathrm{mg}$ (Week $12[P=0.003]$, Week $24[P=0.031]$ ) dose groups. For WOMAC Physical Function, improvements were observed for $0.07 \mathrm{mg}$ (Week 12 $[p=0.021])$ and $0.23 \mathrm{mg}$ (Week $12[p=0.006]$, Week $24[P=0.017])$ dose groups. PtGA improvements were observed for $0.07 \mathrm{mg}$ (Week 12
$[P=0.031])$ and $0.23 \mathrm{mg}$ (Week $12[P=0.010]$, Week $24[P=0.033])$ dose groups.

Conclusion: SM04690, in development as a potential disease-modifying OA drug, showed in this phase $2 b$ study statistically significant improvements from baseline in both the $0.07 \mathrm{mg}$ and $0.23 \mathrm{mg}$ dose groups compared to vehicle $\mathrm{PBO}$ for Pain NRS, WOMAC Pain, WOMAC Physical Function, and PtGA. These data support the continued development of SM04690 as a treatment for knee OA. Phase 3 studies are being planned.

\section{REFERENCE:}

[1] Yazici Y, et al. Arthritis Rheumatol. 2017; 69 (suppl 10).
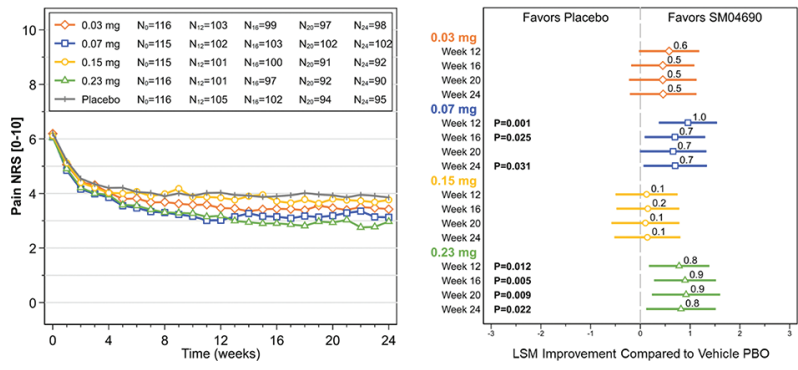

Figure. Actual observations over time and ladder plots depicting least squares mean (LSM) improvement of Pain NRS $( \pm 95 \% \mathrm{Cl}$ ) in SM04690 compared to vehicle PBO, adjusted for baseline.

Disclosure of Interests: Yusuf Yazici Shareholder of: Samumed, LLC Consultant for: Celgene Corporation, BMS, Genentech, Sanofi, Employee of: Samumed, LLC, Timothy McAlindon Grant/research support from: Samumed, LLC, Consultant for: Samumed, LLC, Astellas, Flexion, Pfizer, Regeneron,

Seikugaku, Allan Gibofsky Shareholder of: AbbVie, Amgen, Johnson\&Johnson, Regeneron, Consultant for: AbbVie, Pfizer, Horizon, Celgene, Novartis/Sandoz, Samumed, LLC, Merck, Flexion, Lilly, Speakers bureau: AbbVie, Celgene, Pfizer, Flexion, Lilly, Merck, Nancy Lane Consultant for: Samumed, LLC, Christian Lattermann Shareholder of: Cocoon, Consultant for: Samumed, LLC, Vericel, Cariheal, Joint Restoration Foundation, Nebojsa Skrepnik Grant/research support from: Samumed, LLC, Consultant for: Orthofix, Sanofi, Regeneron, Christopher Swearingen Shareholder of: Samumed, LLC, Employee of: Samumed, LLC, Anita DiFrancesco Shareholder of: Samumed, LLC, Employee of: Samumed, LLC, Jeyanesh Tambiah Shareholder of: Samumed, LLC, Employee of: Samumed, LLC, Marc Hochberg Shareholder of: BriOri Biotech, Theralogix LLC., Consultant for: Bristol Myers Squibb, Eli Lilly, EMD Serono, Novartis Pharma AG, Pfizer Inc., Samumed LLC, Symic Bio Inc., Theralogix LLC, TissueGene Inc. TLC Biopharmaceuticals, Inc., Zynerba, Galapagos, IQVIA, Hoffman LaRoche.

DOI: 10.1136/annrheumdis-2019-eular.5045

\section{THU0459 PREDICTORS ASSOCIATED WITH RAPID PROGRESSION OF KNEE OSTEOARTHRITIS}

Elena Taskina ${ }^{1}$, Ludmila Alekseeva ${ }^{1}$, Natalia Kashevarova ${ }^{1}$, Sergey Anikin ${ }^{1}$, Evgenia Sharapova ${ }^{1}$, Ekaterina Strebkova ${ }^{1}$, Lena Zonova ${ }^{2}$, Tatiana Raskina ${ }^{3}$, Elvira Otteva ${ }^{4}$, Irina Vinogradova ${ }^{5}$, Aleksandr Lila ${ }^{1}{ }^{1}$ V. A. Nasonova Research Institute of Rheumatology, Moscow, Russian Federation; ${ }^{2}$ FSBEI HE Novosibirsk State Medical University, Novosibirsk, Russian Federation; ${ }^{3}$ SBEI HE KemSMU $\mathrm{MOH}$, Kemerovo, Russian Federation; ${ }^{4}$ Regional SBHI CDC MOH Khabarovsky kray, Khabarovsk, Russian Federation; ${ }^{5}$ SHI Ulyanovsk regional affiliated hospital, Ulyanovsk, Russian Federation

Objectives: To identify knee OA rapid progression factors in a multicenter prospective study

Methods: 185 female patients from 5 RF constituent territories aged 4075 with confirmed Kellgren-Lawrence score grade I-III knee OA were included into prospective study after signing the informed consent form Mean age was $59,2 \pm 7,4$ years (42-75), mean BMl-27,7 $\pm 4,4 \mathrm{~kg} / \mathrm{m}^{2}$, mean disease duration-12 $\pm 8,1$ years. Individual patient's medical record included relevant anthropometric data, records from case history and clinical examination, VAS articular pain assessment, WOMAC scores, comorbidities. Instrumental diagnostic methods included plain radiography of knee joints, DEXA of the lumbar spine and femoral neck, MRI examination of knee joints. Stage II knee OA was established in 135 (73\%) out of 185 patients, stage III - in 50 (27\%). 
Results: Knee OA progression (form radiographic stage II to stage III) within 1 year follow up was documented in 15 patients (Group 2 - with progressed $\mathrm{OA}$ ), while 170 patients did not show any progression (Group 1 - no progression). Both groups were comparable in terms of age, age at RA onset, and duration of the disease. Although patients who progressed had higher body weight $(97,1 \pm 14,0$ vs $74,2 \pm 10,8 \mathrm{~kg}, \mathrm{p}<0,0001)$ and $\operatorname{BMl}\left(31,9 \pm 5,8\right.$ vs $\left.27,3 \pm 4,1 \mathrm{~kg} / \mathrm{m}^{2}, \mathrm{p}<0,0001\right)$. Patients from Group II had more intense knee pain during walking (VAS - $65,8 \pm 11,8$ vs 47,5 $\pm 18,7 \mathrm{~mm}(p<0,0003)$, and higher WOMAC: pain- $330,5 \pm 66,0$ vs 237,8 $\pm 85,4 \mathrm{~mm}, \quad \mathrm{p}<0,0001$; function - $1044 \pm 190,4$ vs $859,8 \pm 243,8 \mathrm{~mm}$, $\mathrm{p}<0,007$. Patients from Group II showed higher rates of varus knee alignment $(66,7 \%$ vs $35,3 \%, R R=1,89,95 \% \mathrm{Cl} 1,25-2,85, p=0,02)$ and H.valgus $(86,7 \%$ vs $61,8 \%, R R=1,4,95 \% \mathrm{Cl} 1,11-1,77, p=0,04)$, as well as higher rates of arterial hypertension $(93,3 \%$ vs $71,8 \%$, respectively, $\mathrm{RR}=1,3,95 \% \mathrm{Cl} 1,1-1,53, \mathrm{p}=0,05)$ and type 2 diabetes mellitus (DM) (33,3\% vs 12,9\%, RR=2,57, 95\% Cl 1,14-5,82, $p=0,04)$. MRI showed higher percentage of medial and lateral tibia cartilage defects in Group 2 patients $(57,2 \%$ vs $18,6 \%$, respectively; $R R=3,06,95 \% \mathrm{Cl} 1,74-5,38$, $\mathrm{p}<0,003 ; 57,2 \%$ vs $14 \%, \mathrm{RR}=4,08,95 \%$ Cl 2,23-7,46 $\mathrm{p}<0,0006)$; bone marrow edema (BME) in medial $(71,4 \%$ vs $12,2 \%, R R=5,83,95 \% \quad C l$ $3,38-10,1, p<0,000004)$ and lateral tibial compartments $(21,4 \%$ vs $4,1 \%$, $\mathrm{RR}=5,25,95 \% \mathrm{Cl} 1,47-18,7, \mathrm{p}=0,03$ ); subchondral cysts, occupying more than $25 \%$ of the area in medial and lateral tibial compartments (respectively, $28,6 \%$ vs $7,4 \%, R R=3,84,95 \% \mathrm{Cl} 1,4-10,5, \mathrm{p}<0,03$; and $35,7 \%$ vs $8,8 \%, R R=4,06,95 \%$ Cl 1,7-9,7, $p=0,01$ ). Synovitis (MRI findings) was documented in $100 \%$ patients from Group 2 and in $58,4 \%$ patients without $\mathrm{OA}$ progression ( $\mathrm{RR}=1,71,95 \% \mathrm{Cl} 1,5-2,0, \mathrm{p}=0,002)$. A multivariate (discriminant) analysis showed that the most important risk factors for knee OA progression were: higher body weight, high WOMAC pain score, presence of type $2 \mathrm{DM}$, BME in medial tibial compartment, and cartilage damage in medial tibial compartment (MRI findings). A model capable of predicting rapid progression of knee $\mathrm{OA}$ in an individual patient with high accuracy (area under the ROC-curve $0,925(95 \% \mathrm{Cl} 0,828-1,022)$ ) has been developed based on identified RF and their coefficients.

\begin{tabular}{|l|l|l|}
\hline \multicolumn{1}{|c|}{ Factors } & \multicolumn{1}{c|}{$\begin{array}{c}\text { Discriminant } \\
\text { function } \\
\text { coefficients }\end{array}$} \\
\hline Body weight, $\mathrm{kg}$ & 0,1698 \\
\hline Pain WOMAC, mm & 0,0068 \\
\hline DM type 2 & 1,8387 \\
\hline BME in medial tibia & 1,1848 \\
\hline $\begin{array}{l}\text { Cartilage destruction in the } \\
\text { medial tibial compartment }\end{array}$ & 0,4724 & \\
\hline Constant & 21,6615 & \\
\hline
\end{tabular}

Abstract THU0459 - Figure 1

Conclusion: In a prospective multicenter study, using comprehensive instrumental examination the following key predictors of rapid knee OA progression were identified: excessive body weight, high WOMAC pain score, presence of type $2 \mathrm{DM}$, BME in medial tibial compartment, and cartilage damage in medial tibial compartment (MRI findings).

Disclosure of Interests: Elena Taskina Speakers bureau: Bayer, Sandoz, Boeringer-ingelheim, Ludmila Alekseeva Speakers bureau: Bayer, Boeringer-ingelheim, Gedeon-Richter, Servier, Natalia Kashevarova: None declared, Sergey Anikin: None declared, Evgenia Sharapova: None declared, Ekaterina Strebkova: None declared, Lena Zonova Speakers bureau: Sandoz, Pfizer, Abbvie, Novartis, Bayer, Tatiana Raskina: None declared, Elvira Otteva Speakers bureau: Pfizer, Abbvie, Novartis, Irina Vinogradova Speakers bureau: Pfizer, MSD, Aleksandr Lila Speakers bureau: Sandoz, Pfizer, Abbvie, Novartis, Bayer

DOI: 10.1136/annrheumdis-2019-eular.4525

\section{THU0460 IDENTIFICATION OF POSTOPERATIVE PAIN BIOMARKERS USING GENE EXPRESSION ANALYSES IN THE PERIPHERAL BLOOD OF OSTEOARTHRITIC PATIENTS PRIOR TO JOINT REPLACEMENT}

Elena Tchetina ${ }^{1}$, Kseniya Glemba ${ }^{2}$, Sergey Makarov ${ }^{2} .{ }^{1}$ Nasonova Research Institute of Rheumatology, Immunology and Molecular Biology, Moscow, Russian Federation; ${ }^{2}$ Nasonova Research Institute of Rheumatology, Rheumoorthopaedic, Moscow, Russian Federation

Background: Osteoarthritis $(O A)$ is a chronic rheumatic disease, which involves pain, limited inflammation and local destruction of the knee joint.
OA pain is a major clinical symptom, which limits working capacity and denotes an important indication for joint replacement in the end-stage OA. In spite of significant number of positive outcomes, chronic postoperative pain represents a major adverse consequence of surgery, which is observed in $10-40 \%$ of OA patients. Therefore, identification of patients potentially capable of developing chronic postoperative pain prior to surgery could significantly improve therapy outcome. Central sensitization is in charge of pain symptoms in about $30 \%$ of end-stage OA patients. Several recently identified molecular markers such as cytokines, chemokines, calcium and glutamate transporters, caspases, and proteases has been shown to be responsible for central sensitization. Therefore, we hypothesized that genes related to pain sensitization whose expression is upregulated in about $30 \%$ of the examined end-stage OA patient cohort might be responsible for postoperative pain.

Objectives: To outline an approach for search of biomarkers related to chronic postoperative pain development before joint replacement in the peripheral blood of end-stage OA patients.

Methods: We examined peripheral blood of 26 healthy volunteers (aver age age $55 \pm 8.3$ years old) and 53 end-stage OA patients (average age $56.5 \pm 8.9$ years old) undergoing joint replacement surgery. MMP-9, TIMP1, TGF $\beta 1$, and caspase 3 protein levels were quantified by ELISA. Total RNA isolated from whole blood was used in expression studies for the genes related to central sensitization such as mechanistic target of rapamycin, mTOR; caspase 3; metalloproteinase (MMP)-9; tissue inhibitor of metalloproteinase TIMP1; cathepsins $\mathrm{K}$ and $\mathrm{S}$; interleukin (IL)-1 $\beta$; cyclooxygenase $(\mathrm{COX}) 2$; tumor necrosis factor $(\mathrm{TNF}) \alpha$, and transforming growth (TGF) 31 . These were performed with quantitative real-time RT-PCR.

Results: Retrospective analysis of gene expression in the peripheral blood of end-stage $\mathrm{OA}$ patients before joint replacement surgery revealed that gene expression data for TNF $\alpha$, IL-1 $\beta$, COX2, TGF $\beta 1$, and mTOR were not applicable as these gene expressions were significantly higher compared to healthy controls in all the examined $\mathrm{OA}$ patients. High expres sion of pain associated cathepsin $S$ in $17 \%$ of the examined OA patients and cathepsin $\mathrm{K}$, in $21 \%$ might indicate the possibility of postoperative pain development in these OA patients. In contrast, low expression of caspase 3 in $43 \%$ of the examined OA patients and MMP-9, in $23 \%$, might point toward the absence of postoperative pain in these subjects. Conclusion: Gene expression analysis in the peripheral blood of the end stage OA patients measured before joint replacement surgery might represent an approach for prediction of postoperative pain development.

Disclosure of Interests: : None declared DOI: 10.1136/annrheumdis-2019-eular.5313

\section{THU0461 IDENTIFICATION OF DEFINITIONS OF POOR OUTCOME AFTER TREATMENT OF KNEE OSTEOARTHRITIS: A LITERATURE REVIEW}

Malou te Molder ${ }^{1}$, J.M.H. Smolders ${ }^{2}$, Petra Heesterbeek ${ }^{3}$, Cornelia van den Ende ${ }^{4}$ ${ }^{1}$ Sint Maartenskliniek, Research, Nijmegen, Netherlands; ${ }^{2}$ Sint Maartenskliniek, Orthopaedic Surgery, Nijmegen, Netherlands; ${ }^{3}$ Sint Maartenskliniek, Orthopaedic Research, Nijmegen, Netherlands; ${ }^{4}$ Sint Maartenskliniek, Rheumatology Research, Nijmegen, Netherlands

Background: Total knee replacement (TKR) is considered an effective intervention of the treatment of advanced knee osteoarthritis (OA) (Kellgren \& Lawrence >2). However, a significant proportion of patients could be considered as a poor-responder to TKR (i.e. no or little improvement) in terms of chronic knee pain, functional disability, poor quality of life (QoL), and dissatisfaction after TKR. Both in research and in clinical practice it is challenging to identify those patients with an unfavourable course after TKR. It is difficult though to quantify the proportion of patients with poor response to TKR, as different definitions of, and perspectives (clinician's and patient's) on failure are being used.

Objectives: The aim of this study was to review the literature and summarize definitions of poor response to TKR.

Methods: A systematic search up to 2016 was performed to identify and review previously used definitions of poor response to primary TKR in the literature. Studies were included if dichotomous definitions of outcome after primary TKR were used, if a prospective design was used and in English full text available. The type, amount and combination of domains (i.e. pain and physical function), outcome measures, type of responses (absolute/relative, change/cut-off), values and moments of follow-up used in definitions were summarized.

Results: A total of 44 different dichotomous definitions of poor response to TKR, were extracted from 1849 initially identified studies. 34 definitions incorporated one domain, six definitions comprised two domains and four definitions comprised three domains. Eight different domains were used in identified definitions: pain, physical function (mobility), physical functioning 